\title{
Clinical study of quality of life of traumatic brain injury patients after decompressive craniectomy and related influencing factors
}

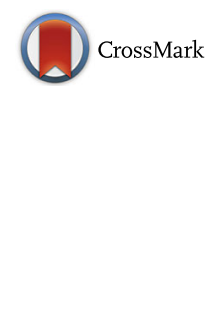

\author{
Roodrajeetsing Gopaul, Zong Dang Wei, Jun Yan, Fan Yong Gong and Shao Wen Xiao*
}

\begin{abstract}
Background: Decompressive craniectomy (DC) in traumatic brain injury (TBI) patients has been subject of debate for neurosurgeons since long time. Our goal in this study is to evaluate the quality of life of these patients and to look at the problem from their point of view.

Methods: Quality of Life after Traumatic Brain injury (QOLIBRI) instrument is was applied to 105 TBI patients who performed DC. Age, gender, the mode of injury and level of education, time from TBI to DC, lowest GCS score post-injury, presence of a corneal reflex, whether patients performed reconstructive cranioplasty or not, blood pressure, patient temperature, midline shift on CT scan, fasting blood glucose, whether patients performed rehabilitation therapy, days of use of mannitol and barbiturates sedation were recorded.

Results: Sex of the patient, educational background, time between TBI to perform DC surgery, pupillary response of patient before surgery, systolic and diastolic blood pressures, fasting blood glucose, rehabilitation and use of barbiturates did not prove to have any statistical significant impact on the patient's QOLIBRI score. Young patients were found to be scoring more in the social domain $(P=0.02)$. Higher Glasgow Coma Score (GCS) patients scored statistically better in the cognitive $(p=0.00)$, self ( 0.00$)$, daily life $(p=0.00)$, social $(p=0.00)$, emotion $(p=0.00)$ and total QOLIBRI $(p=0.00)$ score. Interestingly, the longer the time interval between TBI and time at QOLIBRI instrument application, the lower the score for cognitive $(p=0.00)$, self $(p=0.04)$, daily life $(p=0.02)$, emotion $(p=0$. $05)$ and total QOLIBRI $(p=0.02)$ score. Reconstructive cranioplasty proved to positively affect the emotion $(p=0.05)$, social life $(p=0.01)$ and total QOLIBRI $(p=0.05)$ score. Temperature had a negative influence on the cognitive $(p=0$. $01)$, self $(p=0.01)$ and daily life score $(p=0.01)$. Midline shift on $C T$ imaging had a negative influence on cognitive $(p=0.00)$, self $(p=0.00)$, daily life $(p=0.00)$, social $(p=0.00)$, emotion $(p=0.05)$ and total QOLIBRI $(p=0.00)$ score.
\end{abstract}

Conclusion: QOLIBRI proves to be an excellent tool for evaluation of TBI patients who undergone DC. Regular assessment comparisons can help to tailor personalized rehabilitation treatment strategies for patients.

Keywords: Traumatic brain injury, Decompressive craniectomy, QOLIBRI, Rehabilitation, Quality of life

\section{Background}

From ages of 1 to 44 years, traumatic brain injury (TBI) is the major with health-related injury associated with mortality [1]. TBI is defined as an alteration in brain function or other evidence of brain pathology caused by an external force [2]. At present there are about 10 million people affected annually by TBI [3]. TBI can severely and permanently change a person's life [4]. Truelle et al. define

\footnotetext{
* Correspondence: $1140136341 @ q q . c o m$

First Affiliated Hospital of Guangxi Medical University, 6, Shuang Yong Road, 530021 Nanning, Guangxi Province, People's Republic of China
}

TBI as a "silent epidemic" and they believe that this "silent epidemic" is not widely known and its importance to public health is insufficiently recognized $[5,6]$.

TBI induces excitotoxic surges which facilitate an influx of calcium into the cell which in a progressive and delayed manner cause non-inflammatory swelling and hence program further neural loss [7, 8]. Edema increases the volume of intracranial contents, which translates into increased intracranial pressure (ICP). A vicious cycle of brain swelling, increased ICP, reduction in blood supply and oxygen delivery, energy failure and further 
swelling is developed which further enhances brain injury hence precipitating death [9-11].

Non-invasive therapeutic methods are used as first line measures for ICP control [9, 11]. Decompressive craniectomy (DC), first reported by Annandale in 1894, is a promising rescue therapeutic strategy for refractory cerebral edema in cases of failure of first line non-invasive measures [12]. The rationale behind DC is to convert an injury within a closed box, with a fixed volume and limited reserve, into an open system with increased capacity to accommodate mass [13].

Reduced health related quality of life (HRQOL) has been identified in individuals with TBI when compared with the healthy population [14-17]. Traditionally, outcomes from TBI have been assessed by objective functional indicators such as recovery from disability, or return to work and productivity, while subjective physical, social and psychological effects were neglected [6]. Patient-reported outcomes (PRO), where patients capture their own perspective, has become a central endpoint of rehabilitation and has led to increased interest in evaluation of quality of life post TBI [18]. As documented by von Steinbuechel, neurology and neurosurgery have adapted to HRQOL as patient reported outcome relatively late [16].

QOLIBRI is a multidimensional view of HRQOL, encompassing well-being and functioning in physical, psychological (cognitive and emotional), social, and daily life domains, with the patient viewed as the best source of information on his or her subjective state $[6,19]$. The psychometric properties, correlations with neuropsychological tests and cross cultural validity of QOLIBRI have proved to overcome all the short comings in the previously present HRQOL instruments [20]. QOLIBRI contains 37 items in 6 domains, Cognition, Self, Daily Life and Autonomy, Social Relationships, Emotion and Physical Problems respectively [6].

Several studies have supported the use of DC in not only TBI but also following ischemic stroke, subarachnoid hemorrhage and cases of severe intracranial infection [21]. Findings obtained so far on DC are mixed; some groups report a relatively high prevalence of favorable outcomes while others report much lower prevalence of favorable outcomes [15]. In order to better understand the PRO on HRQOL, we conducted a retrospective study on TBI patients who performed DC.

\section{Methods}

\section{Patient population}

TBI patients undergoing DC from January 2008 to December 2013 were selected from The First Affiliated Hospital of Guangxi Medical University database. A total of 105 patients were enrolled to take the 37-itemed QOLIBRI instrument. At completion, 50 participants were willing to be re-interviewed after 2 weeks for the test-retest analysis.

\section{Inclusion criteria}

Criteria for applying QOLIBRI instrument: Patients must be adults (age 16 years or older) and 17-68 years at recruitment to the study; 6 to 96 months after injury, capacity to give informed consent; adequate cognitive and behavioral functioning to understand, answer and cooperate. Criteria for DC: appearance of definite unilateral or bilateral brain swelling and a midline shift of at least $5 \mathrm{~mm}$ on the computed tomography (CT) scan with poor initial Glasgow coma scale $(\mathrm{GCS})$ score $(\leq 8)$; neurological worsening (a worsening of GCS score $\geq 2$ points) and aggravation of pupillary response to light during initial medical therapy; bilateral fixed pupils with an intact brain stem reflex; a swollen brain despite hematoma evaluation.

\section{Exclusion criteria}

Pre-injury or current cognitive disability interfering with assessments; spinal cord injury; severe psychiatric diseases; ongoing severe drug addiction; previously diagnosed with hypertension; a diagnosed terminal illness; multiple severe trauma and burns.

\section{Treatment plan and operative procedures}

All patients underwent CT scanning of the brain in the emergency room on presentation. The mainstay for TBI patient management is medical. Our hospital operates on a protocol that includes head elevation, adequate oxygenation, fluid resuscitation, mild hyperventilation to reduce cerebral blood volume and osmotic diuretics. When non-invasive methods tend to fail, we assess the patient for ventriculostomy, craniotomy for hematoma removal or craniectomy to convert the 'closed' intracranial compartment into an 'open' one. DC reduces ICP and enhances blood flow, it has been shown that the larger the craniectomy, the greater the reduction of ICP. It has been shown that a $10 \mathrm{~cm}$ diameter bone flap with durotomy provides an additional volume of around $50 \mathrm{ml} .70 \%$ of volume expansion of a DC is achieved through wide dural opening and $30 \%$ by bone removal only. Usually a bone flap of $12 \mathrm{~cm}$ is recommended [9, 22].

Decompressive craniectomy was performed by removing large portion of frontotemporoparietal cranium $(>12 \mathrm{~cm})$ for lesions confined to one cerebral hemisphere. Patients with bifrontal or anterior cranial fossa lesions underwent bilateral frontal craniectomy. The reference points used for bone flaps were at the pterion of frontal bone, the parietal eminence and in the temporal squamous areas. Temporal squama was rongered out until the floor of the middle cranial fossa was exposed. For patients with bilateral decompression, a frontal median segment of the bone, 
measuring about $3-4 \mathrm{~cm}$ in width along the sagittal sinus was saved to prevent damage to the sagittal sinus and to serve as a framework for later cranioplasty. Radial dural incisions are usually preferred over circumferential incisions giving adequate exposure to the hematoma. After craniectomy, epidural hematoma (EDH) and subdural hematoma (SDH) were evacuated when present. Brain parenchymal hemorrhagic contusions were removed in cases with persistent and significant brain swelling after craniectomy and hematoma evacuation. Artificial dura was used in majority of the patients and was secured with several sutures. Other duroplasty were done by harvesting the fascia overlying the temporal muscle. All patients underwent duroplasty to prevent cortical adhesions. Thin large gel-foam (roughly $0.5 \mathrm{~cm}$ thickness and $4 \times 5 \mathrm{~cm}$ size) pieces were placed between the dura and muscle layer for post-operative bleeding control and prevention of adherence between the dura and temporalis muscle. This gel-foam layer also facilitated the dissection plane for later cranioplasty.

\section{Postoperative management and additional operation}

After the decompression surgery propofol infusion is usually stopped, patient return to the neurosurgery intensive care unit (NICU) and conventional medical management, including hyperosmotic agents, neuroprotective drugs and antibiotics are used. Patients are ventilated until they regain consciousness and GCS is evaluated. A decision to extubated the patient or to continue with elective ventilation is taken. The next morning, all patients undergo a CT scan to evaluate the patient post-operatively. All patients (with exception to 2 patients in whom the bone defect healed itself), titanium cranioplasty using 3-D computer modelling of skull defects were carried out after 3-6 months after craniectomy. A ventriculo-peritoneal shunt was performed if the diagnosis of hydrocephalus was confirmed.

\section{Data collection}

After ethics clearance was obtained, data collection was performed retrospectively from review of medical charts and database of First Affiliated Hospital of Guangxi Medical University. Patients were recruited from the database on the basis of the coding of surgical procedures and diagnoses, allowing access to all patients undergoing DC in our institution. After receiving the informed consent of the patients, demographic data of patients, e.g. age, gender, previous medical history, the mode of injury and level of education were recorded. Level of education was divided as high and low: fewer than 10 years of education was considered low and greater than 10 years of education as high. When possible and often the case, missing data for education were imputed based on the type of work. For example, a participant whose occupation was listed as "farmer" was categorized as low education. Prehospital and hospital data of patients e.g. the lowest GCS score post-injury, presence of unilateral or bilateral dilated pupils, presence of a corneal reflex in the case of bilateral dilated pupils, whether patients performed reconstructive cranioplasty or not, blood pressure, patient temperature, midline shift on CT scan, fasting blood glucose, whether patients performed rehabilitation therapy, days of use of mannitol and barbiturates sedation were recorded.

The QOLIBRI instrument was the outcome measure in the present study. The first part taps on the responder's satisfaction with their HRQOL in 4 domains comprising cognition, self, daily life and autonomy and social relationships. The second part relates to how bothered the responders rate themselves after TBI in 2 domains concerning emotions and physical problems. Each item (37 in total) is scored on a 5-point scale, from 1 (not-at-all satisfied) to 5 (very satisfied), with reverse scoring on the bothered subscales. The QOLIBRI was scored according to an algorithm published by von Steinbuchel et al. [14]. Missing item scores on each subscale were imputed by the scale mean if less than one third of the responses were missing. Raw scores were transformed into a score range of 0 (lowest) to 100 (highest). Individual subscale scores and a total score were calculated. The interviewer determined if the participant was able to respond to the self-report questionnaire independently. If yes, the questionnaires were completed in the clinic. If no, questionnaire was completed by telephone or in a face to face interview.

\section{Statistical analysis}

Data analysis was carried out in SPSS 16.0 for windows (SPSS, Inc., Chicago, IL, USA). Item scores on the QOLIBRI "bothered" scales were reversed to match the "satisfaction" questions. Means were calculated for each QOLIBRI scale, prorated if no more than one-third of items were missing. A total QOLIBRI score was also calculated as the mean of all individual items, using prorating if necessary. Results are reported as the number (and percentage) of patients or mean \pm standard deviation unless otherwise specified. A difference with a $p$ value of $\leq 0.05$ was regarded as statistically significant (two tailed test).

Skewness was present in the reported data and seems to be common in response to clinical scales. Extreme skewness can however create problems for analysis using correlations, reducing the probability that a scale will show strong relationships with other measures, and its reliability (or precision of measurement) of a scale. Skewness was checked but, however, some moderately skewed items were included, to capture a range of impairments [19]. Multivariate regression analyses were performed for the influence of sex, age, educational level, 
TBI to DC time, Worst GCS score, pupillary response, TBI to questionnaire time, whether performed cranioplasty, systolic blood pressure, diastolic blood pressure, temperature of patient, midline shift on computed tomography scan, fasting blood glucose, whether or not treated in a rehabilitation center, days of use of mannitol and use of barbiturate sedation to the 6 different QOLIBRI domain scores and total score.

For the internal consistency of the scales, which reflects their reliability, was assessed using the Cronbach's $\alpha$, and the fit of individual items to each scale was examined by correlating the item with the total for the other items in the scale. Cronbach's $\alpha$ and corrected item-total correlations (CITCs) were calculated. Test-retest reliability is one of the most important measures of reliability for questionnaires. The test-retest reliability of the QOLIBRI scales was assessed using the intra-class correlation coefficient (ICC), calculated between the scale means on two occasions (retested on average 14 days after initial testing). The conventional interpretation of the ICC is that values of 0.40 0.75 are fair to good and values over 0.75 are excellent [19].

\section{Results}

\section{Descriptive}

A total of 105 participants were enrolled. Demographic and clinical characteristics of the sample are illustrated in Table 1. $77(73.3 \%)$ were males, the mean age was 36.5 years ( $\mathrm{SD}=14.2$ years). The cumulative frequency of patients below the age of 50 years old was $80 \% .33 .3 \%$ of the patients were injured due to falling, $49.5 \%$ were injured in road traffic accidents, $13.3 \%$ in violence and $3.8 \%$ were injured while working. Educational level of patients were classified as $\leq 10$ years of schooling $(71.4 \%)$ and $>11$ years of schooling $(28.6 \%)$. The time from TBI to perform DC was divided into 3 groups, less than $6 \mathrm{~h}(23.8 \%)$, between 7 to $24 \mathrm{~h}(44.8 \%)$ and $\geq 25 \mathrm{~h}(31.4 \%)$. The GCS (Glasgow Coma Scale) of patients was retrieved and divided into 3 groups, 3-5 (40\%), 6-8 (43.8\%) and 9-12 (16.2\%). Pupillary response was divided into 3 groups, bilaterally unreactive pupils (9.5\%), unilaterally unreactive pupil (53.3 \%) and bilaterally reactive pupils (37.1\%).

\section{Psychometric properties of QOLIBRI items}

Detailed item characteristics of the QOLIBRI-items are shown in Table 2. All the corrected item-total correlations (CITCs) were greater than 0.58 . Internal consistency of the scales and the total score estimated by Cronbach's $\alpha$ met standard psychometric criteria (Tables 3 and 4). The total QOLIBRI score of the population was $62.5(\mathrm{SD}=12.5)$ as illustrated in Fig. 1.

\section{Test-retest reliability}

A total of 50 participants agreed to apply the QOLIBRI instrument again after a 2 week interval. The test-retest
Table 1 Demographic and clinical characteristics of sample

\begin{tabular}{|c|c|c|}
\hline Characteristics & $\mathrm{n}$ & $\%$ \\
\hline \multicolumn{3}{|l|}{ Gender } \\
\hline Male & 77 & 73.3 \\
\hline Female & 28 & 26.7 \\
\hline \multicolumn{3}{|l|}{ Age } \\
\hline 16-20 years & 17 & 16.2 \\
\hline $21-30$ years & 27 & 25.7 \\
\hline $31-40$ years & 19 & 18.1 \\
\hline $41-50$ years & 21 & 20.0 \\
\hline $51-60$ & 16 & 15.2 \\
\hline $61-65$ & 5 & 4.8 \\
\hline Mean & (36.5 \pm 14.2 years) & \\
\hline \multicolumn{3}{|l|}{ Cause } \\
\hline Falling & 35 & 33.3 \\
\hline Road accident & 52 & 49.5 \\
\hline Violence & 14 & 13.3 \\
\hline Occupational & 4 & 3.8 \\
\hline \multicolumn{3}{|l|}{ Education level } \\
\hline$\leq 10$ years & 75 & 71.4 \\
\hline$>11$ years & 30 & 28.6 \\
\hline \multicolumn{3}{|l|}{ TBI-DC time } \\
\hline$<6 h$ & 25 & 23.8 \\
\hline $7-24 \mathrm{~h}$ & 47 & 44.8 \\
\hline$\geq 25 \mathrm{~h}$ & 33 & 31.4 \\
\hline \multicolumn{3}{|l|}{ Worst GCS } \\
\hline $3-5$ & 42 & 40.0 \\
\hline $6-8$ & 46 & 43.8 \\
\hline $9-12$ & 17 & 16.2 \\
\hline \multicolumn{3}{|l|}{ Pupillary response } \\
\hline Bilaterally unreactive & 10 & 9.5 \\
\hline Unilaterally unreactive & 56 & 53.3 \\
\hline Bilaterally reactive & 39 & 37.1 \\
\hline \multicolumn{3}{|l|}{ Reconstruction of Skull } \\
\hline No & 46 & 43.8 \\
\hline Yes & 59 & 56.2 \\
\hline \multicolumn{3}{|l|}{ Fasting blood glucose } \\
\hline$\leq 6.1 \mathrm{mmol} / \mathrm{L}$ & 44 & 41.9 \\
\hline$\geq 6.2 \mathrm{mmol} / \mathrm{L}$ & 61 & 58.1 \\
\hline \multicolumn{3}{|l|}{ Midline Shift } \\
\hline$\leq 8 \mathrm{~mm}$ & 64 & 61.0 \\
\hline$\geq 8.1 \mathrm{~mm}$ & 41 & 39.0 \\
\hline
\end{tabular}

intraclass correlations (ICC) ranged from 0.94 to 0.74 for separate scales. The ICC for the total QOLIBRI was 0.86 . 
Table 2 Item characteristics

\begin{tabular}{|c|c|c|c|c|c|}
\hline Scale & Item & Mean & SD & Skewness & $\begin{array}{l}\text { Cronbach's a } \\
\text { If item removed }\end{array}$ \\
\hline \multirow[t]{7}{*}{ Cognition } & Concentrate & 72.86 & 17.02 & -0.64 & 0.95 \\
\hline & Express yourself & 74.76 & 19.76 & -1.29 & 0.96 \\
\hline & Remember & 73.33 & 17.08 & -0.47 & 0.95 \\
\hline & Plan and solve problem & 72.14 & 20.60 & -1.26 & 0.95 \\
\hline & Decisions & 70.95 & 19.03 & -1.32 & 0.96 \\
\hline & Find way & 74.28 & 21.50 & -1.15 & 0.96 \\
\hline & Speed of thinking & 69.76 & 18.24 & -0.86 & 0.95 \\
\hline \multirow[t]{7}{*}{ Self } & Energy & 71.43 & 18.81 & -1.14 & 0.95 \\
\hline & Motivation & 67.14 & 20.89 & -0.86 & 0.95 \\
\hline & Self-esteem & 70.95 & 21.69 & -1.03 & 0.96 \\
\hline & Way you look & 70.47 & 18.60 & -0.98 & 0.96 \\
\hline & Achievements & 65.95 & 20.25 & -0.90 & 0.96 \\
\hline & Self-perception & 69.29 & 19.07 & -1.40 & 0.95 \\
\hline & Own future & 69.29 & 17.42 & -1.91 & 0.95 \\
\hline \multirow[t]{7}{*}{ Autonomy } & Independence & 72.62 & 22.07 & -1.09 & 0.96 \\
\hline & Get out and about & 67.62 & 22.18 & -0.90 & 0.96 \\
\hline & Domestic activities & 71.67 & 23.27 & -1.04 & 0.96 \\
\hline & Run personal finances & 67.38 & 21.12 & -0.93 & 0.96 \\
\hline & Participation & 66.19 & 22.19 & -0.50 & 0.96 \\
\hline & Social-leisure activities & 67.86 & 21.00 & -1.00 & 0.96 \\
\hline & In charge of life & 69.29 & 22.54 & -0.97 & 0.96 \\
\hline \multirow[t]{6}{*}{ Social } & Affection to others & 75.00 & 18.01 & -1.26 & 0.96 \\
\hline & Family members & 77.62 & 18.96 & -0.85 & 0.96 \\
\hline & Friends & 73.10 & 17.23 & -1.16 & 0.96 \\
\hline & Partner & 66.35 & 17.01 & -0.71 & 0.95 \\
\hline & Sex life & 75.00 & 25.00 & -1.49 & 0.96 \\
\hline & Attitude towards others & 70.47 & 17.60 & -1.08 & 0.96 \\
\hline \multirow[t]{5}{*}{ Emotions } & Loneliness & 53.57 & 21.77 & 0.34 & 0.96 \\
\hline & Boredom & 51.90 & 23.69 & 0.26 & 0.95 \\
\hline & Anxiety & 53.81 & 18.91 & 0.15 & 0.95 \\
\hline & Depression & 54.76 & 19.64 & 0.38 & 0.95 \\
\hline & Anger/aggression & 56.90 & 24.12 & -1.26 & 0.96 \\
\hline \multirow[t]{5}{*}{ Physical } & Slowness/clumsy & 50.76 & 21.67 & 0.15 & 0.95 \\
\hline & Other injuries & 53.57 & 20.64 & 0.25 & 0.96 \\
\hline & Pain & 51.90 & 22.17 & 0.27 & 0.96 \\
\hline & See/hear & 48.10 & 28.73 & 0.27 & 0.96 \\
\hline & TBI-effects & 46.43 & 19.74 & -0.22 & 0.96 \\
\hline
\end{tabular}

Multivariate analyses of demographic and clinical factors to QOLIBRI scale

Multivariate regression was used to find how the QOLIBRI domain scores were individually influenced by the independent variables (Table 5). Sex of the patient, educational background, time between TBI to perform DC surgery, pupillary response of patient before surgery, systolic and diastolic blood pressures, fasting blood glucose, rehabilitation and use of barbiturates did not prove to have any statistical significant impact on the patient's QOLIBRI score. Young patients were found to be scoring more in the social domain $(p=0.02)$. Higher 
Table 3 Scale properties

\begin{tabular}{lllcl}
\hline & Mean & SD & Cronbach's a & CITC \\
\hline Cognition & 72.56 & 15.74 & 0.95 & 0.85 \\
Self & 69.22 & 16.24 & 0.95 & 0.92 \\
Daily & 68.95 & 19.34 & 0.96 & 0.58 \\
Social & 59.84 & 15.87 & 0.96 & 0.76 \\
Emotion & 54.19 & 15.12 & 0.95 & 0.81 \\
Physical & 50.15 & 17.25 & 0.96 & 0.64 \\
Total & 62.49 & 12.50 & 0.95 & 1.00 \\
\hline
\end{tabular}

Glasgow Coma Score (GCS) patients scored statistically better in the cognitive $(p=0.00)$, self $(0.00)$, daily life $(p=0.00)$, social $(p=0.00)$, emotion $(p=0.00)$ and total QOLIBRI $(p=0.00)$ score. Interestingly, the longer the time interval between TBI and time at QOLIBRI instrument application, the lower the score for cognitive $(p=0.00)$, self $(p=0.04)$, daily life $(p=0.02)$, emotion $(p=0.05)$ and total QOLIBRI $(p=0.02)$ score. Reconstructive cranioplasty proved to positively affect the emotion $(p=0.05)$, social life $(p=0.01)$ and total QOLIBRI $(p=0.05)$ score. Temperature had a negative influence on the cognitive $(p=0.01)$, self $(p=0.01)$ and daily life score $(p=0.01)$. Midline shift on CT imaging had a negative influence on cognitive $(p=0.00)$, self $(p=0.00)$, daily life $(p=0.00)$, social $(p=0.00)$, emotion $(p=0.05)$ and total QOLIBRI $(p=0.00)$ score.

\section{Discussion}

The use of decompressive craniectomy in neurosurgery has been widely discussed. Authors have noticed ethical contradiction in that absolute priority is given to preserving life while it remains unclear whether it results in a significant improvement in the quality of life of the patient [23]. To our knowledge, surprisingly, there has been no previous study to evaluate the quality of life of patients who performed decompressive craniectomy after traumatic brain injury. QOLIBRI, a disease specific instrument, assesses health related quality of life (HRQoL) of patients from different dimensions and help to keep tract of the present condition of patient and upon follow ups shows progress of patients from different aspects. In TBI patients who require DC, quick decisions must be made due to severity of the condition. Patient's decision and consent is substituted by surrogate decision makers who make choices between life and death. Risks of unacceptable badness (RUB) is a situation in which survivors live in a state which they would regard as unacceptably bad is often ignored [23].

Our search in PubMed, Cochrane and Google Scholar with keywords "TBI", "DC", "Quality of Life", "HRQoL" and/or "QOLIBRI" revealed about 1200 articles. After careful evaluation by our authors, 115 articles were selected and 32 articles were used in this study. This is the first article to evaluate the patient's perspective on his/ her current quality of life after decompressive craniectomy due to traumatic brain injury.

Though intracranial pressure seems to be alleviated by the removal of the cranial bone and the dura matter, the patient's outcome, hence quality of life, has been questioned by many researchers [24-26]. DC is intended to increase the expansion volume of the edematous brain tissue in the closed cranial box by removing a bone flap (usually $12 \mathrm{~cm}$ large), thereby increasing compliance which will result in a shift to the right of the pressurevolume curve. Intracranial pressure (ICP) is clinically controlled and oxygenation of the brain tissues are maintained which, in theory, will decrease secondary TBI injuries [22, 27]. However, the Extended Glasgow Outcome Scale after 6 months in patients who undergone DC plus standard care was significantly worse compared to the patients who received standard care alone [26].

Decompressive craniectomy may be regarded as a simple procedure by many, but the fact that two surgical procedures are required- removal of bone flap (craniotomy) followed by repair of the defect (cranioplasty) - may be associated with significant complications [22, 25]. Early complications of craniectomy are associated with changes in interstitial pressures and brain compliance, cerebrospinal fluid circulation, cerebral blood perfusion and cerebral vasoreactivity autoregulation [13]. Syndrome of the trephined, usually later in craniectomy, is characterized by

Table 4 Test-Retest comparisons

\begin{tabular}{|c|c|c|c|c|c|}
\hline & $n$ & Test mean (SD) & Re-Test mean (SD) & Cronbach a & ICC \\
\hline Cognition & 50 & $73.36(14.7)$ & $75.24(12.8)$ & 0.95 & 0.91 \\
\hline Self & 50 & $69.80(15.8)$ & $72.44(13.33)$ & 0.97 & 0.94 \\
\hline Daily Life and Autonomy & 50 & $69.50(18.9)$ & $73.52(12.4)$ & 0.85 & 0.74 \\
\hline Social Relationships & 50 & $61.42(16.4)$ & $64.95(11.9)$ & 0.90 & 0.82 \\
\hline Emotions & 50 & $53.40(17.2)$ & $57.00(13.3)$ & 0.92 & 0.85 \\
\hline Physical Problem & 50 & $47.82(19.3)$ & $50.90(15.1)$ & 0.96 & 0.92 \\
\hline QOLIBRI Total & 50 & $62.55(12.8)$ & $68.07(10.0)$ & 0.92 & 0.86 \\
\hline
\end{tabular}




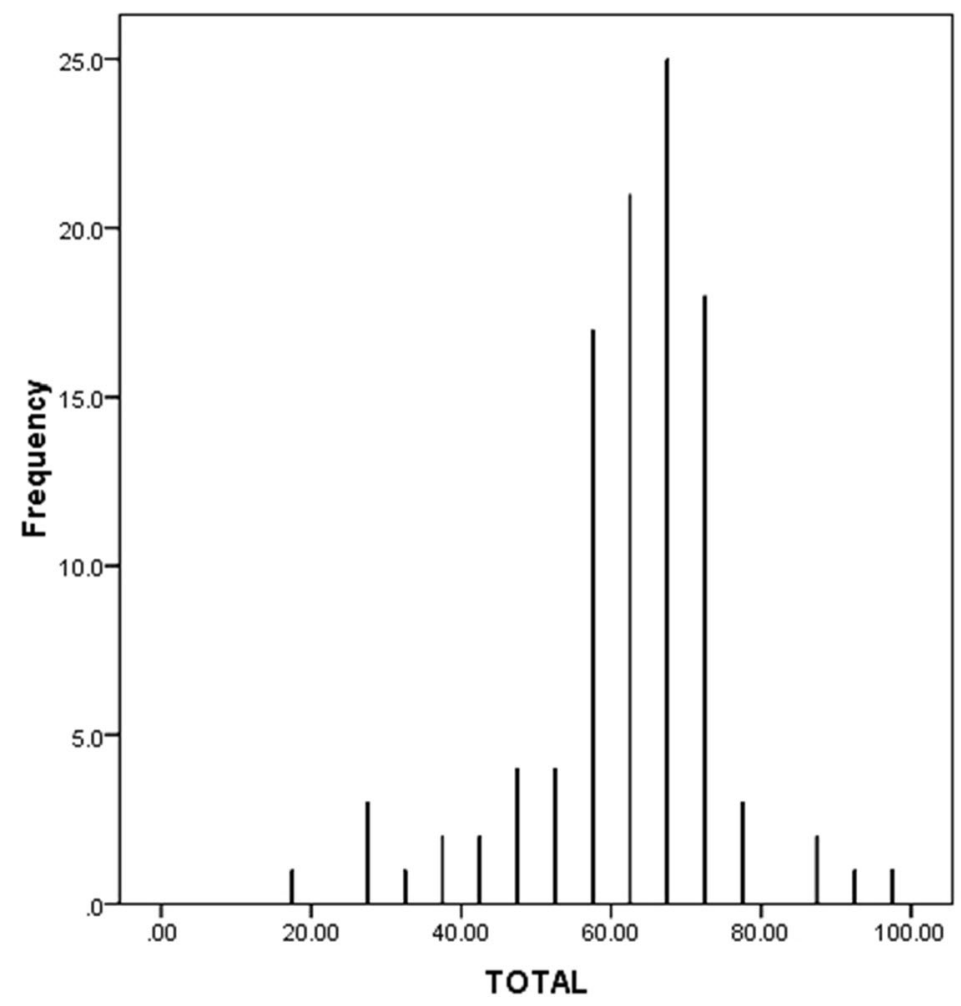

Mean $=62.4887$

$\begin{aligned} \text { Stc. Dev. } & =12.50141 \\ \mathrm{~N} & =105\end{aligned}$

Fig. 1 Bar chart of TOTAL QOLIBRI scoring

Table 5 Multivariate regression B coefficients with corresponding $p$ values in brackets for domains of the QOLIBRI index in relation to characteristics of the sample

\begin{tabular}{|c|c|c|c|c|c|c|c|}
\hline & $\begin{array}{l}\text { Cognition } \\
\text { (p) }\end{array}$ & $\begin{array}{l}\text { Self } \\
\text { (p) }\end{array}$ & $\begin{array}{l}\text { Daily Life } \\
\text { (p) }\end{array}$ & $\begin{array}{l}\text { Social } \\
\text { (p) }\end{array}$ & $\begin{array}{l}\text { Emotions } \\
\text { (p) }\end{array}$ & $\begin{array}{l}\text { Physical } \\
\text { (p) }\end{array}$ & $\begin{array}{l}\text { Total } \\
\text { (p) }\end{array}$ \\
\hline Sex & $-2.73(0.40)$ & $-2.73(0.43)$ & $0.36(0.93)$ & $2.04(0.54)$ & $1.00(0.76)$ & $-4.24(0.28)$ & $-1.02(0.70)$ \\
\hline Age & $-1.69(0.16)$ & $-1.16(0.35)$ & $-2.24(0.14)$ & $-2.81 *(0.02)$ & $0.81(0.50)$ & $-2.39(0.09)$ & $-1.57(0.10)$ \\
\hline Education Level & $-4.50(0.27)$ & $-3.27(0.45)$ & $-6.98(0.18)$ & $-2.51(0.55)$ & $0.64(0.88)$ & $-9.01(0.07)$ & $-4.24(0.20)$ \\
\hline TBI-DC Time & $-1.11(0.58)$ & $-1.49(0.48)$ & $-0.85(0.74)$ & $0.45(0.83)$ & $2.65(0.19)$ & $-3.28(0.18)$ & $-0.63(0.70)$ \\
\hline Min GCS Score & $8.56 *(0.00)$ & $8.39 *(0.00)$ & $9.17^{*}(0.00)$ & $7.76^{*}(0.00)$ & $6.78^{*}(0.00)$ & $0.58(0.82)$ & $6.90 *(0.00)$ \\
\hline Pupillary Response & $-0.49(0.85)$ & $-0.002(0.99)$ & $1.47(0.66)$ & $2.21(0.41)$ & $-0.55(0.83)$ & $1.44(0.65)$ & $0.66(0.76)$ \\
\hline TBI-Questionnaire & $-2.50 *(0.00)$ & $-1.83 *(0.04)$ & $-2.57^{*}(0.02)$ & $-0.85(0.34)$ & $-1.70 *(0.05)$ & $-0.84(0.42)$ & $-1.73 *(0.02)$ \\
\hline Cranioplasty & $3.40(0.28)$ & $4.73(0.15)$ & $4.04(0.30)$ & $5.92 *(0.01)$ & $5.66 *(0.05)$ & $6.12(0.10)$ & $4.82 *(0.05)$ \\
\hline Systolic BP & $1.34(0.69)$ & $1.95(0.57)$ & $3.10(0.46)$ & $0.96(0.78)$ & $3.16(0.34)$ & $6.33(0.11)$ & $2.78(0.30)$ \\
\hline Diastolic BP & $-0.89(0.79)$ & $0.77(0.83)$ & $2.79(0.51)$ & $0.46(0.89)$ & $-2.63(0.43)$ & $-1.96(0.62)$ & $-0.27(0.92)$ \\
\hline Temperature & $-8.84^{*}(0.01)$ & $-9.44^{*}(0.01)$ & $-10.80 *(0.01)$ & $-3.08(0.36)$ & $-1.74(0.60)$ & $-5.24(0.18)$ & $-4.28^{*}(0.11)$ \\
\hline Midline Shift & $-11.72 *(0.00)$ & $-13.09 *(0.00)$ & $-13.77^{*}(0.00)$ & $-15.41 *(0.00)$ & $-6.35 *(0.05)$ & $-1.95(0.61)$ & $-9.72 *(0.00)$ \\
\hline Fasting Glucose & $2.25(0.48)$ & $2.48(0.45)$ & $1.49(0.71)$ & $-2.63(0.42)$ & $0.32(0.92)$ & $-1.24(0.74)$ & $0.46(0.86)$ \\
\hline Rehabilitation & $1.00(0.78)$ & $0.86(0.80)$ & $3.21(0.44)$ & $3.98(0.24)$ & $-5.90(0.07)$ & $-7.58(0.06)$ & $-0.72(0.79)$ \\
\hline Mannitol & $-9.52 *(0.00)$ & $-7.04 *(0.03)$ & $-11.21 *(0.00)$ & $-5.22^{*}(0.09)$ & $1.28(0.70)$ & $4.77(0.19)$ & $-4.54^{*}(0.05)$ \\
\hline Barbiturate & $-3.06(0.34)$ & $-0.83(0.80)$ & $-2.94(0.46)$ & $-2.83(0.38)$ & $-2.69(0.40)$ & $2.71(0.47)$ & $-1.59(0.54)$ \\
\hline
\end{tabular}

* $p \leq 0.05$ : statistically significant value

TBI-DC time from traumatic brain injury to decompressive craniectomy, Min GCS score minimum Glasgow Coma scale score, TBI-Questionnaire: Time of initial traumatic brain injury to application of QOLIBRI instrument; Systolic BP systolic blood pressure, Diastolic BP diastolic blood pressure 
severe headache, dizziness, undue fatigability, poor memory, irritability, epilepsy, discomfort and psychiatric symptoms. [25] Infection, subdural hygroma, brain parenchymal damage, instability of implant and injury at the unprotected craniectomy site are complications associated with cranioplasty [13, 22, 25].

Bullinger et al. recommended that quality of life of TBI patients should reflect the point of view of patients, significant others and health care providers, though differences in perception may exist [28]. Studies reviewed by Nicole V.S. et al. indicated that moderate to severely TBI affected patients lived with a perceptually changed body image and self-image. Feelings of having lost their way, often struggling for a new normalcy after changes in physical and social conditions are new perspectives of TBI patients [29]. The QOLIBRI items do not focus only on disabilities which are helpful to patients making then identify not only weaknesses but also strengths and the impact on their own life situations. This is particularly effective for rehabilitation as it enhances strengths and facilitates adjustments rather than trying to compensate for disabilities [30].

The ultimate goal of health care and rehabilitation following TBI is to return the person to full health or to enable him or her to maintain as high a health related quality of life (HRQOL) as possible. Subjective opinion of patients is crucial in prioritizing therapeutic goals as it takes into account their personal needs, values and hopes thus improving goal attainment. It also facilitates the therapeutic alliance, thus helping the participant to build a new life via a new ego-identity, in his/her own cultural, social and environmental context [30, 31]. QOLIBRI is an ideal 37-item questionnaire, which can be completed in less than $20 \mathrm{~min}$, and can be regularly used in clinics for patients follow-up. It can help to identify and set appropriate goals for therapy. Score shifts in individual domains may reflect areas of life where gains or drawbacks consequent to treatment are made $[6,19,30]$.

$83.8 \%$ of our patient population had worse GCS score less than 8. The mean total QOLIBRI score was 62.5 $(\mathrm{SD}=12.5)$, maximum score of $72.6(\mathrm{SD}=15.7)$ was noted in the cognition domain and minimum score of $50.2(\mathrm{SD}=17.3)$ was noted in the physical domain. We found that our "satisfied" scale scores were higher than the previously reported scores, whereas the "bothered" scale score were lower than that reported earlier [14, 18-20, 32]. These scores may have been influenced by the fact that severely injured patients have a greater sense of "survivorship" along with greater levels of social support. Also, because of impaired self-awareness, patients self-report may create a false impression that they have better neurological recovery from TBI than is the actual case [18, 32]. However, it has been earlier reported that patients may have adapted to new dimensions after TBI as when asked whether they would have consented to surgical intervention even if they had known their eventual outcome, answers were in the affirmative. Patients may adapt to their disability and recalibrate to as what they believe to be an acceptable quality of life and perceive an "unfavorable" outcome not necessarily as unacceptable as is perceived by others [24]. However, interestingly, the longer the time interval between TBI and time at QOLIBRI instrument application, the lower the score for cognitive $(p=0.00)$, self $(p=0.04)$, daily life $(p=0.02)$, emotion $(p=0.05)$ and total QOLIBRI $(p=0.02)$ score. We speculate that these patients, at the beginning, because of the impairment of their self-awareness, may actually underestimate the harm caused to them, but as time passes they become more aware and tend to appreciate the severity of their condition.

Patients whose total QOLIBRI score is less than 60 meet the hospital anxiety and depression scale (HADS) criteria of probable anxiety or depression and patients with total score less than 40 meet HADS criteria for diagnosis of both conditions [30]. Our total QOLIBRI score was 62.5. Siponski et al. studied 157 patients of which $59.2 \%$ had GCS scale less than 8 (severe), and reported total QOLIBRI score less than ours [18]. However, other studies reported higher total score than ours $[14,19]$. DC after TBI did not seem to be a definite factor to plunged total QOLIBRI score.

A separate issue was identified when dealing with TBI patients who undergone DC. Quality of life of patients as perceived by patients and relatives may be contradictory. Cases were noted where patients believed to be perfectly normal whereas relatives complained of increased temper, bad decision makings, poor hygiene and throwing tantrums among others. There were also cases where relatives believed that patient were recovering perfectly whereas patients themselves were complaining of difficulties in adaptation to the new lifestyle post TBI and DC. Especially, young female patients who had skull defect prior to cranioplasty were unwilling to go out and socialize with friends as they were terrified with the "alien" look. Reconstructive cranioplasty has an overall positive influence on the emotion domain $(p=0.05)$ the total QOLIBRI score $(p=0.05)$. This supports the findings of Cho et al. that in appropriately selected patients early cranioplasty must be performed [25]. We believe that if we can apply the QOLIBRI instrument in both patient and caregivers each time on follow up, harmony can be brought in the patient-caregiver relationship. TBI directly affects the patient but indirect harm to the caregivers is usually ignored, proper guidance and support to the caregivers must also be part of rehabilitation treatment. 


\section{Conclusion}

Traumatic brain injuries mostly affect young patients when they are financially unstable and deal with major life problems like looking for employment, getting married and child bearing. QOLIBRI is a new disease specific instrument recommended by the international consensus group on quality of life after TBI. Cronbach's $\alpha$, which reflects the reliability and internal consistency of scales proved to be very effective and test-retest reliability of the scores was acceptable.

The rehabilitation of TBI patients who undergo DC is a multi-disciplinary process with involvement of assessment from several professionals. The 6 domains of the QOLIBRI instrument can evaluate the patients from different perspectives and patients can be re-evaluated routinely in the rehabilitation phase as soon as they are aware enough to respond appropriately. After each evaluation the present score can be compared with the previous score and areas of weakness can be implemented in the further treatment plans by the rehabilitation task force.

QOLIBRI is in line with the current rehabilitation measures as it is also multidisciplinary involving not only a rehabilitation therapist but also a psychiatrist and willpower of the patient and caregiver. As DC is a topic of debate among neurosurgeons, we would strongly recommend the use of QOLIBRI in evaluation of traumatic brain injury patients who undergone DC to shed further light on this issue.

\section{Study limitations}

The First Affiliated Hospital of Guangxi Medical University is a tertiary medical health center, majority of the patients come from different cities and counties. Some patients reach our hospital only for the surgery and continue rehabilitation in other hospitals, so our follow up data cannot reflect $100 \%$ of the TBI patients who undergone DC. The QOLIBRI items are score on a 1 to 5 scale. This score needs to be computed on a 100 score scale by subtracting 1 and then multiplying by 25 . We found in some patients difficulties to rate themselves on a 1 to 5 score. They were more convenient and confident on a 100 score scale. This may be because $71.4 \%$ of our patients had education level less than 10 years, the proper estimation on such small scale proved challenging. Also we found that many of our patients were reluctant to answer the sex life item in social relationships scale. Further improvements in this scale can bring better compliance of patients to QOLIBRI instrument.

\section{Future directions}

When patients are affected by TBI and undergo DC, the patient and caregivers are both involved. All the studies published so far evaluate the patient from the health officer's or patient's point of view. We believe that patients and caregivers should both be more actively involved in the rehabilitation process. QOLIBRI can be assessed by both patient and caregiver and an idea of the domain scores differences can be used to harmonize the situation.

The clinical importance of DC on TBI patients has been proved and questioned at several instances. However, studies on the quality of life of these patients are very few. If larger studies can be carried out using QOLIBRI to evaluate the TBI patient's perspective after DC, this may be very helpful information.

\section{Abbreviations \\ DC: Decompressive Craniectomy; TBI: Traumatic brain injury; QOLIBRI: Quality of life after traumatic brain injury; HRQoL: Health related quality of life; RUB: Risks of unacceptable badness; ICP: Intracranial pressure; WHO: World Health Organization; PRO: Patient-reported outcomes; CT: Computed tomography; GCS: Glasgow Coma Scale; NICU: Neurosurgery intensive care unit; CITCs: Corrected item-total correlations; ICC: Intra-class correlation coefficient}

\section{Acknowledgement}

This is not applicable.

\section{Authors' contributions}

RG conceived of the study, and participated in its design and coordination and helped to draft the manuscript. RG and ZDW participated in the sequence alignment and drafted the manuscript. JY, WSX participated in the design of the study and performed the statistical analysis. All authors read and approved the final manuscript.

\section{Competing interests}

The authors declare that they have no competing interests.

\section{Consent for publication}

Patients agreed upon admission and prior to surgery that as a teaching hospital, their information can be used for scientific purposes.

\section{Ethics approval and consent to participate}

This study received consent from the Ethical Committee of First Affiliated Hospital of Guangxi Medical University.

Received: 23 September 2015 Accepted: 27 July 2016

Published online: 22 September 2016

\section{References}

1. Mangat HS. Severe traumatic brain injury. Continuum Lifelong Learning Neurol. 2012;18(3):532-46.

2. Johnston AJ, Steiner LA, Coles JP, Chatfield DA, Fryer TD, Smielewski $P$, et al. Effect of cerebral perfusion pressure augmentation with dopamine and norepinephrine on global and focal brain oxygenation after traumatic brain injury. Intensive Care Med. 2004;30(5):791Y797.

3. Mak CHK, Wong SKH, Wong GK, Ng S, Wang KKW, Lam PK, et al. Traumatic brain injury in the elderly: is it as bad as we think? Curr Tran Geriatr Gerontol Rep. 2012;1:171-8.

4. Khan F, Baguley IJ, Cameron ID. Rehabilitation after traumatic brain injury. Rehabil Med MJA. 2003;178:290-5.

5. Zitnay GA, Zitnay KM, Povlishock JT, Hall ED, Marion DW, Trudel T, et al. Traumatic brain injury research priorities: the Conemaugh international brain injury symposium. J Neurotrauma. 2008;25:1135-52.

6. Steinbuchel N, Wilson L, Gibbons H, Hawthorne G, Hofer S, Schmidt S, et al. Quality of life after brain injury (QOLIBRI): scale validity and correlates of quality of life. J Neurotrauma. 2010;27:1157-65.

7. Frantseva M, Perez VJL, Tonkikh A, Adamchik Y, Corlen PL. Neurotrauma/ neuro degeneration and mitochondrial dysfunction. Prog Brain Res. 2002;137:171-6.

8. Bullock R, Statham J, Patterson D, Wyper D, Hadley D, Teasdale E. The time course of vasogenic edema after focal human head injury - evidence from SPECT mapping of blood brain barrier defects. Acta Neurochir (Wien) Suppl. 1990;51:286-8. 
9. Khalil IM, Sudumbrekar SM, Shashivadhanan, Sengupta SK, Rappai TJ. Decompressive craniectomy in traumatic brain injury Rationale and practice. Indian J Neurotrauma. 2010;7(1):9-12.

10. Hutchinson PJ, Corteen E, Czosnyka M, Mendelow AD, Menon DK, Mitchell P, et al. Decompressive craniectomy in traumatic brain injury: the randomized multicenter RESCUEicp study. Acta Neurochir Suppl. 2006;96:17-20.

11. INTISO D, LOMBARDI T, GRIMALDI G, IAROSSI A, TOLFA M, RUSSO M, et al. Long-term outcome and health status in decompressive craniectomized patients with intractable intracranial pressure after severe brain injury. Brain Inj. 2011;25(4):379-86.

12. Gouello G, Hamel O, Asehnoune K, Bord E, Robert R, Buffenoir K. Study of the long-term results of decompressive craniectomy after severe traumatic brain injury based on a series of 60 consecutive cases. Scientific World Journal. 2014;2014(207585):10.

13. Shirley IS. Complications of decompressive craniectomy for traumatic brain injury. Neurosurg Focus. 2009;26(6):E7.

14. Helene LS, Cecilie R, Audny A, Juan CAL, Toril S, Unni S, et al. Health-related quality of life 12 months after severe traumatic brain injury: a prospective nationwide cohort study. J Rehabil Med. 2013;45:785-91.

15. ROGERS SJ, BROWNE AL, VIDOVICH M, HONEYBUL S. Defining meaningful outcomes after decompressive craniectomy for traumatic brain injury: Existing challenges and future targets. Brain Inj. 2011;25(7-8):651-63.

16. Steinbuechel N, Petersen C, Bullinger $M$, and the QOLIBRI Group. Assessment of health-related quality of life in persons after traumatic brain injury- development of the Qolibri, a specific measure. Acta Neurochir. 2005; [Suppl] 93:43-9.

17. WHO QOL. The World Health Organization Quality of Life Assessment (WHOQOL): development and general psychometric properties. Soc Sci Med. 1998;46:1569-85.

18. Siponkoski ST, Wilson L, Steinbüchel N, Sarajuuri J, Koskinen S. Quality of life after traumatic brain injury: Finnish experience of the QOLIBRI in residential rehabilitation. J Rehabil Med. 2013;45:00.

19. Steinbuchel N, Wilson L, Gibbons H, Hawthorne G, Hofer S, Schmidt S, et al. Quality of life after brain injury (QOLIBRI): scale development and metric properties. J Neurotrauma. 2010;27:1167-85.

20. Hawthorne G, Kaye AH, Gruen R, Houseman D, Bauer I. Traumatic brain injury and quality of life: initial Australian validation of the QOLIBRI. J Clin Neurosci. 2011;18:197-202.

21. Honeybul S. Decompressive craniectomy for severe traumatic brain injury: a review of its current status. J Neurol Neurophysiol. 2012;2155-9562.

22. Eghwrudjakpor PO, Allison AB. Decompressive craniectomy following brain injury: factors important to patient outcome. Libyan J Med. 2010;5:4620.

23. Honeybul S, Gillett GR, Ho KM, Lind CRP. Neurotrauma and the rule of rescue. J Med Ethics. 2011;37:707e710.

24. Honeybul S, Janzen C, Kruger K, Ho KM. Decompressive craniectomy for severe traumatic brain injury: is life worth living? I Neurosurg. 2013;119:1566-75.

25. Cho KC, Park SC, Choe IS, Seo DH. Safety and efficacy of early cranioplasty after decompressive craniectomy in traumatic brain injury patients. J Korean Neurotraumatol Soc. 2011;7:74-7.

26. Cooper DJ, Rosenfeld JV, Murray L, Arabi YM, Davies AR, D'Urso P. Decompressive craniectomy in diffuse traumatic brain injury. $N$ Engl I Med. 2011;364:16.

27. Ki TK, Jin KP, Seok GK, Kyung SC, Do SY, Dong KJ, et al. Comparison of the effect of decompressive craniectomy on different neurosurgical diseases. Acta Neurochir. 2009;151:21-30

28. Bullinger M, Azouvi P, Brooks N, Basso A, Christensen AL, Gobiet W, et al. Quality of life in patients with traumatic brain injury-basic issues, assessment and recommendations. Results of a consensus meeting. Restor Neurol Neurosci. 2002:20:111-24.

29. Steinbuechela N, Richtera S, Morawetza C, Riemsmae R. Assessment of subjective health and health-related quality of life in persons with acquired or degenerative brain injury. Curr Opin Neurol. 2005;18:681-91.

30. JEAN LT, SANNA K, GRAEME H, JAANA S, RITA F, KLAUS WW, et al. Quality of life after traumatic brain injury: the clinical use of the QOLIBRI, a novel disease-specific instrument. Brain Inj. 2010;24(11):1272-91.

31. Hawthorne G, Gruen RL, Kaye AH. Traumatic brain injury and long-term quality of life: findings from an Australian study. J Neurotrauma. 2009;26:1623-33.

32. Lin YN, Chu SF, Liang WM, Chiu WT, Lin MR. Validation of the quality of life after brain injury in Chinese persons with traumatic brain injury in Taiwan. J Head Trauma Rehabil. 2013. doi:10.1097/HTR.0b013e3182816363.

\section{Submit your next manuscript to BioMed Central and we will help you at every step:}

- We accept pre-submission inquiries

- Our selector tool helps you to find the most relevant journal

- We provide round the clock customer support

- Convenient online submission

- Thorough peer review

- Inclusion in PubMed and all major indexing services

- Maximum visibility for your research

Submit your manuscript at www.biomedcentral.com/submit
C Biomed Central 